\title{
Isolation, Partial Sequencing, and Expression of Pathogenesis-Related cDNA Genes from Pepper Leaves Infected by Xanthomonas campestris pv. vesicatoria
}

\author{
Ho Won Jung and Byung Kook Hwang \\ Department of Agricultural Biology, Korea University, Seoul 136-701, Korea \\ Accepted 18 August 1999.
}

Specific cDNAs showing differential expression in bacteria-infected pepper leaves as opposed to healthy leaves were isolated from a pepper cDNA library from hypersensitive response (HR) lesions of leaves infected with an avirulent strain of Xanthomonas campestris pv. vesicatoria. Among a total of 282 cDNA clones tested, 36 individual cDNA genes $(13 \%)$ hybridized strongly or differentially to the cDNA probes from bacteria-infected leaves. Ten Capsicum annuum-induced (CAI) genes encoding putative thionin, lipid transfer protein I and II, osmotin (PR-5), class I chitinase, $\beta$-1,3-glucanase, SAR 8.2, stellacyanin, leucine-rich repeat protein, and auxin-repressed protein were identified. Two $C A I$ genes showed little or no sequence homology to the previously sequenced plant genes. Transcripts of the $C A I$ genes were strongly or preferentially induced in pepper tissues by infection with $X$. campestris pv. vesicatoria or Phytophthora capsici, and by abiotic elicitor treatment. In particular, most of the $C A I$ genes were strongly induced in pepper tissues by ethephon and methyl jasmonate.

Some plants defend themselves by a variety of constitutive defense barriers and active protective mechanisms accompanied by an array of biochemical and physical changes. One of the most-studied plant defense responses is the synthesis of a group of host-encoded proteins such as pathogenesis-related (PR) proteins. Recently, it has been suggested that several families of small, basic, and cysteine-rich antimicrobial proteins such as thionin (Bohlman et al. 1988), lipid transfer protein (Garcia-Olmedo et al. 1995), and plant defensin (Terras et al. 1992) may play a significant role in plant defense responses. Some PR proteins have indeed been found to have antifungal activity in vitro (Bol et al. 1990). The genetically engineered plants overexpressing PR proteins have been

Corresponding author: Byung Kook Hwang; Telephone: 82-2-32903061; Fax: 82-2-925-1970; E-mail: bkhwang@kuccnx.korea.ac.kr

Nucleotide and/or amino sequence data have been deposited in the EMBL/GenBank data base under accession numbers from AF082705 to AF082729. shown to be resistant to pathogen infection (Alexander et al. 1993). Moreover, PR proteins can be induced in plant tissues by treatment with abiotic elicitors. Some well-known chemical inducers of PR proteins include polyacrylic acid, ethephon, benzoic acid, salicylic acid (SA), 2,6-dichloroisonicotinic acid (INA), benzo(1,2,3)thiadiazole-7-carbothioic acid S-methyl ester (BTH), and DL- $\beta$-amino-n-butyric acid (BABA) (Kessmann et al. 1994; Friedrich et al. 1996; Sunwoo et al. 1996).

Differentially expressed mRNAs in plants have been identified by differential display (Ling and Pardee 1992), differential screening, subtractive hybridization (Kouchi and Hata 1993), and polymerase chain reaction (PCR)-based cloning. Recently, automated partial cDNA sequencing has also been conducted on randomly selected appropriate cDNAs to generate expressed sequence tags (ESTs) for the goal of functional identification, mapping, and comparison of all plant genes (Keith et al. 1993).

In our earlier studies, some PR proteins such as chitinases and $\beta$-1,3-glucanases were found to be greatly induced and accumulated in pepper leaves or stems infected by $X$. campestris pv. vesicatoria or Phytophthora capsici (Kim and Hwang 1994; Lee and Hwang 1996). These hydrolases purified from pepper stems showed antifungal activity in vitro against some fungal pathogens (Kim and Hwang 1996, 1997). Here, we report on the isolation of specific cDNA genes, differentially or strongly expressed in pepper leaves infected with avirulent strain Bv5-4a of X. campestris pv. vesicatoria, using the differential hybridization technique (Gadea et al. 1996). Subsequently, partial sequences of the isolated cDNA clones were assigned presumed identities based on sequence comparison with previously known genes. In addition, we describe how the expression of transcripts of selected cDNA clones is strongly induced in pepper leaves or stems by pathogen infection and abiotic elicitor treatment. Some specific genes that may play a role in defense response in pepper plants also are characterized.

To search for cDNAs showing preferential expression in pepper leaves infected with avirulent strain Bv5-4a of X. campestris pv. vesicatoria, differential hybridization of the pepper cDNA library was performed with each of two cDNA probes 
from healthy and bacteria-infected leaves (Fig. 1). The pepper cDNA library was constructed from hypersensitive response (HR) lesions of pepper leaves $24 \mathrm{~h}$ after inoculation with the avirulent strain Bv5-4a of $X$. campestris pv. vesicatoria (Jung 1998). The pepper leaf tissue used for cDNA library was at the onset of HR. To clone genes for PR proteins from the pepper cDNA library, cDNA inserts over $0.6 \mathrm{~kb}$ in size, which were amplified by PCR from 284 randomly selected plaques, were applied in an equal quantity (200 ng) as dots from A1 to X10 on duplicate nylon membranes, except H11, H12, P11, $\mathrm{P} 12$, and X11, X12 as controls. In most cases, blotting signals showed stronger hybridization with the cDNA probe from infected leaves than with that from healthy, uninfected leaves. Among a total of 282 clones tested, 36 individual cDNA clones hybridized strongly or preferentially to the digoxigenin (DIG)-labeled, single-stranded cDNA probe from the bacteriainfected leaves, but did not hybridize or hybridized weakly to the cDNA probe from healthy leaves. The 36 differentially expressed cDNA clones were designated CAIs ( Capsicum annuum-induced genes).

Differential hybridization technique has been successfully used to isolate defense-related genes ectopically expressed in viroid-infected tomato plants (Gadea et al. 1996). It seemed to be an effective strategy for the isolation of a large number of PR genes differentially expressed in pepper plants. To effectively screen specific cDNA clones coding for PR proteins in pepper plants by differential hybridization, however, equal quantities of individual cDNA clones should be applied as dots on nylon membranes. DIG-labeled, single-stranded cDNA probes amplified by mRNAs from healthy or bacteriainfected leaves also were used in similar quantities for hybridization with the blotted duplicate membranes. Based on the analysis of 282 randomly selected cDNAs, a total of 36 $(13 \%)$ cDNA clones were found to be differentially or strongly induced in pepper leaves by avirulent strain Bv5-4a of $X$. campestris pv. vesicatoria infection. Some of the cDNA clones weakly expressed in the bacteria-infected leaves may be excluded in this screening.

A total of 36 individual $C A I$ clones that were strongly induced in bacteria-infected pepper leaves were sequenced and assigned their probable functions by comparing sequence homology with other known plant genes in a search of the GenBank data bases. Sequence alignment and homology searches allowed classification of the 36 cDNA clones into $25 C A I$ groups (Table 1). Seventeen out of 25 groups revealed their postulated functions. However, the $8 \mathrm{cDNA}$ clones that

\section{Healthy leaves}

\section{Infected leaves}

\section{Scheme}
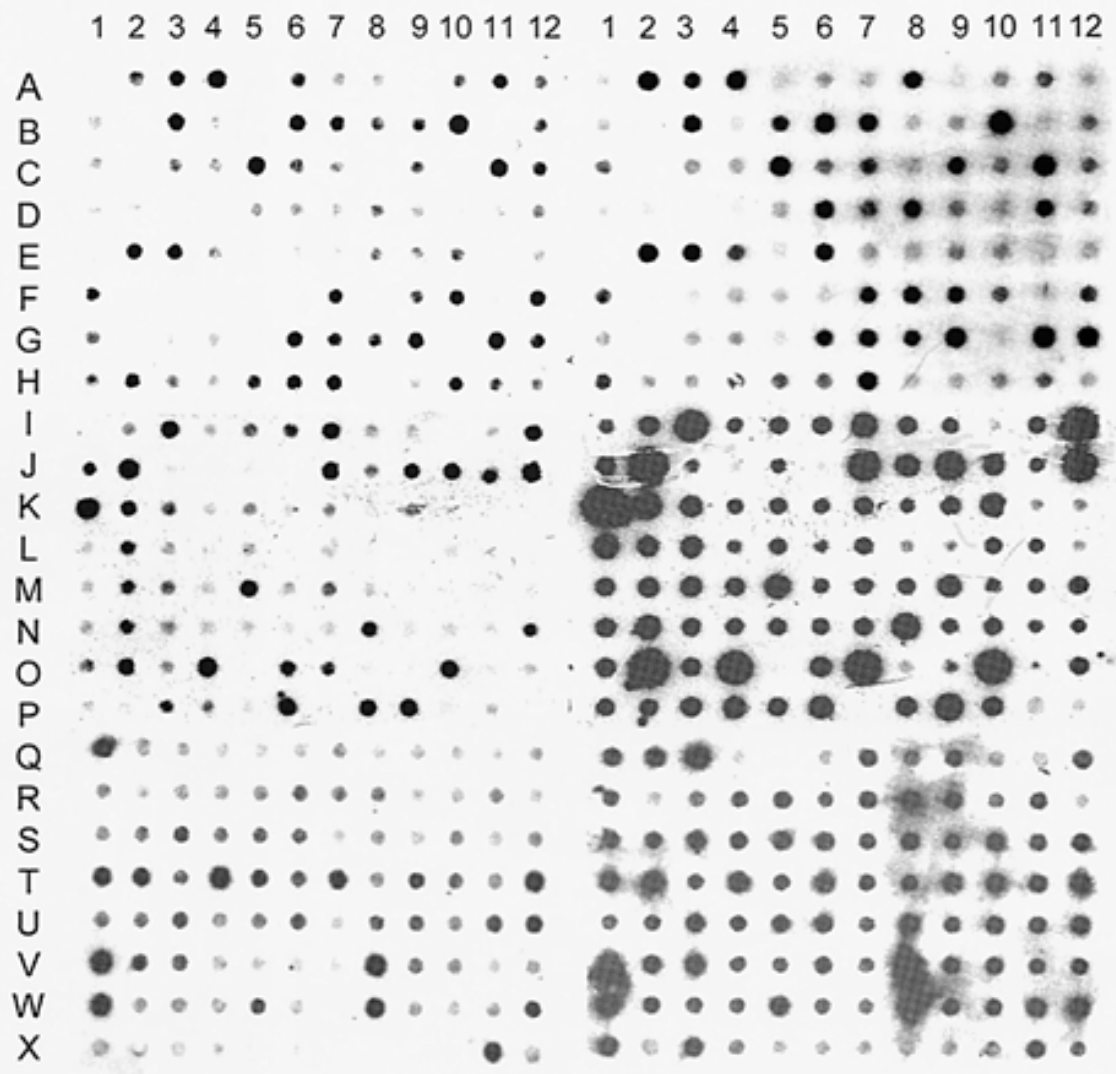

$\begin{array}{llllllllllll}1 & 2 & 3 & 4 & 5 & 6 & 7 & 8 & 9 & 10 & 11 & 12\end{array}$

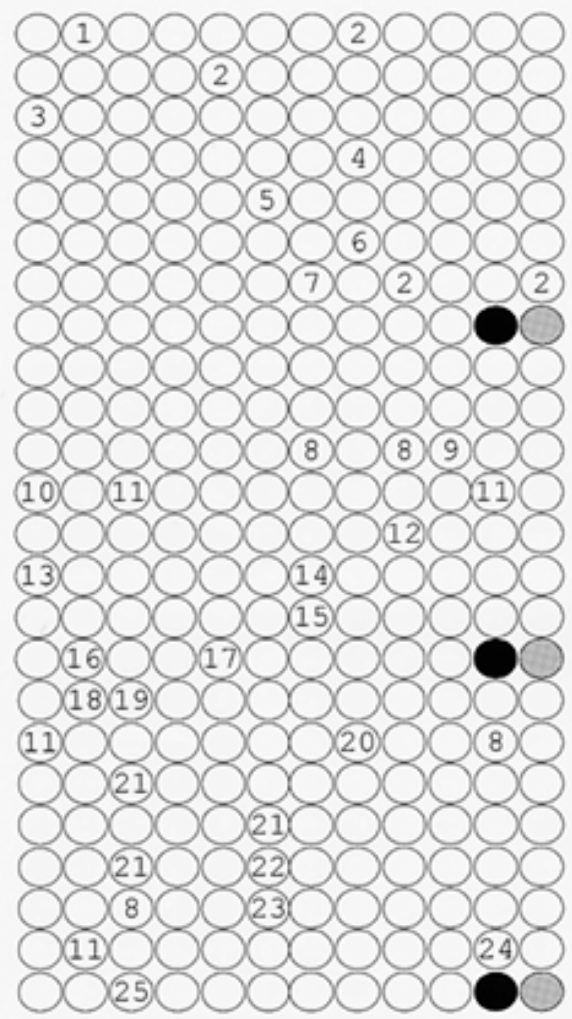

Fig. 1. Differential hybridization of a $\lambda$-ZAP II cDNA library from pepper leaves infected with avirulent strain Bv5-4a of Xanthomonas campestris pv. vesicatoria. Randomly selected cDNAs on the nylon membrane were hybridized with digoxigenin-labeled, single-stranded cDNA probes that were synthesized from total RNA of (I) healthy and (II) bacteria-infected leaves with avian myeloblastosis virus (AMV) reverse transcriptase. Clones hybridizing strongly or preferentially with cDNA probes from infected leaves are indicated as serial numbers (III). Capsicum annuum 25S rRNA probe was used as a positive control (black circles). pBluescript SK(-) plasmid DNA also was used as a negative control (gray circles). 
showed little or no sequence homology to genes in the data bases were presumed to encode novel PR proteins. Four genes, CAI2, CAI8, CAI11, and CAI21, encoding putative thionin-like protein, trehalose phosphate synthase, $60 \mathrm{~S}$ ribosomal protein, and lipid transfer protein, respectively, were more greatly induced in pepper leaves than were other $C A I$ genes by bacteria infection. These $C A I$ genes were provisionally identified based on the following criteria: nucleic acid and/or amino acid significant identities, an unbroken open reading frame, the presence of appropriate conserved residues, and the expression pattern of $C A I$ gene transcripts in plants. The GenBank accession numbers of the partial cDNA sequences of $C A I$ genes are shown in Table 1.

In general, data from the coding region at the $5^{\prime}$ end of cDNAs may be much more informative than those from $3^{\prime}$ untranslated regions (UTRs). The double-stranded cDNA clones in the pBluescript SK(-) vector were sequenced over 300 bp with T3 primer (5'; Amersham, Cleveland, OH) flanking the multiple cloning site, because $5^{\prime}$ end partial sequences longer than $150 \mathrm{bp}$ were found to be the most useful for similarity searches. Data base comparisons of the CAI genes revealed that the 36 cDNA clones could be classified into 25 groups. Of these, nine cDNA clones were confirmed to have a high degree of sequence similarity to previously sequenced defense- or pathogenesis-related genes: thionin (CAI2), osmotin (CAI5 and CAI19), lipid transfer protein (CAI6 and CAI21), chitinase (CAI9), SAR 8.2 (CAI15), $\beta$-1,3glucanase $(C A I 20)$, and leucine-rich repeat (LRR) protein (CAI23). Interestingly, the $C A I 23$ gene showed a high level of homology to LRR protein that may mediate ligand binding in the extracellular receptor domain that subsequently activates signal transduction mechanisms (Kobe and Deisenhofer 1994; Stone and Walker 1995).

The deduced amino acid sequences of representative cDNAs CAI2, CAI6, CAI15, CAI19, CAI21, and CAI23 are shown in Figure 2. The $C A I$ genes that were randomly selected from the cDNA library of bacteria-infected pepper leaves contained an apparent single open reading frame initiated by the ATG initiation codon. CAI2 contained five cysteine residues located in similar positions, and a tyrosine residue at position 21, as in all other toxic thionins (Fig. 2A) (Bohlmann 1994). The partial amino acid sequences of CAI2 showed 50 to $54 \%$ homology with other plant genes corresponding to the $\gamma$-thionin-like protein. The partial amino acid sequences of CAI6 and CAI21 showed 53 to $74 \%$ homology with lipid transfer proteins from other organisms (Fig. 2B). The N-terminal amino acid partial sequence of CAI6 was found to share $47 \%$ homology with the partial sequence of $C A I 21$. The highly conserved spacing of the six cysteine residues, one of the characteristics of lipid transfer protein, also was found in the N-terminal partial sequences of CAI6 and CAI21. The partial deduced amino acid sequences of $C A I 15$ are shown in Figure 2C. Sequence alignments of CAI15 with pepper SAR8.2A (S. C. Lee and B. K. Hwang, unpublished) indicated a high degree of homology (80\%; Fig. 2C). Amino acid sequences of CAI15 also had 38 to $44 \%$ homology with SAR 8.2 proteins from tobacco plants (Ward et al. 1991). The partial deduced amino acid sequences of CAI19 are shown in Figure 2D. Among the total of 16 cysteine residues, the three cysteine residues in-

Table 1. Genes differentially expressed in pepper leaves infected by avirulent strain of Xanthomonas campestris pv. vesicatoria

\begin{tabular}{|c|c|c|c|c|c|c|}
\hline Clone & Accession no. ${ }^{a}$ & Clones (no.) ${ }^{b}$ & cDNA size(kb) & Homology & High score $^{c}$ & $E$ value $^{\text {d }}$ \\
\hline CAI1 & AF082705 & 1 & 0.7 & No significant similarity & $?$ & $?$ \\
\hline CAI2 & AF082706 & 4 & 0.6 & Tomato $\gamma$-thionin-like protein (U20591) & 65 & $7 e-11$ \\
\hline CAI3 & AF082707 & 1 & 0.6 & No significant similarity & $?$ & $?$ \\
\hline CAI4 & AF082708 & 1 & 0.6 & No significant similarity & $?$ & $?$ \\
\hline CAI5 & AF082709 & 1 & 0.6 & Tobacco osmotin-like protein (X95308) & 176 & $8 \mathrm{e}-44$ \\
\hline CAI6 & AF082710 & 1 & 0.7 & Tobacco lipid transfer protein (D13952) & 102 & $9 \mathrm{e}-22$ \\
\hline $\mathrm{CAI} 7$ & AF082711 & 1 & 0.7 & No significant similarity & $?$ & ? \\
\hline CAI8 & AF082712 & 4 & 0.9 & Arabidopsis trehalose phosphate syntase (AAC24048) & 153 & $2 \mathrm{e}-37$ \\
\hline CAI9 & AF082713 & 1 & 1.2 & Potato class I chitinase (U02605) & 443 & e-123 \\
\hline CAI10 & AF082714 & 1 & 0.9 & Wheat asparagine syntase (L28008) & 123 & $5 e-29$ \\
\hline CAI11 & AF082715 & 4 & 0.8 & Turnip 60S ribosomal protein (Z24739) & 160 & $3 e-39$ \\
\hline CAI12 & AF082716 & 1 & 1.0 & Cucumber stellacyanin (U65511) & 82 & $2 \mathrm{e}-15$ \\
\hline CAI13 & AF082717 & 1 & 1.0 & No significant similarity & $?$ & $?$ \\
\hline CAI14 & AF082718 & 1 & 0.9 & No significant similarity & $?$ & $?$ \\
\hline CAI15 & AF082719 & 1 & 0.8 & Tobacco SAR 8.2a (M97194) & 36 & 0.058 \\
\hline CAI16 & AF082720 & 1 & 0.8 & Maize profilin (X73279) & 91 & $4 \mathrm{e}-18$ \\
\hline CAI17 & AF082721 & 1 & 0.9 & No significant similarity & $?$ & $?$ \\
\hline CAI18 & AF082722 & 1 & 1.0 & No significant similarity & $?$ & $?$ \\
\hline CAI19 & AF082723 & 1 & 1.0 & Tomato osmotin-like protein (X66416) & 168 & $3 e-48$ \\
\hline CAI20 & AF082724 & 1 & 1.4 & Tobacco $\beta$-1,3-glucanase $(\mathrm{X} 07280)$ & 119 & $8 \mathrm{e}-27$ \\
\hline CAI21 & AF082725 & 3 & 0.9 & Tomato lipid transfer protein (U81996) & 145 & $1 \mathrm{e}-34$ \\
\hline CAI22 & AF082726 & 1 & 0.8 & $\begin{array}{l}\text { Potato translationally controlled tumor protein homolog } \\
\quad(\mathrm{P} 43349)\end{array}$ & 111 & $1 \mathrm{e}-24$ \\
\hline CAI23 & AF082727 & 1 & 1.0 & Tomato LRR protein (X95269) & 101 & $2 \mathrm{e}-21$ \\
\hline CAI24 & AF082728 & 1 & 0.9 & Maize protein translation factor SUI1 homolog (P56330) & 104 & $2 \mathrm{e}-22$ \\
\hline CAI25 & AF082729 & 1 & 0.9 & Apricot auxin-repressed protein (U93273) & 70 & $5 e-12$ \\
\hline
\end{tabular}

a The GenBank accession numbers of $C A I$ clones are listed.

${ }^{\mathrm{b}}$ A total of 36 individual cDNA clones differentially expressed by bacterial infection were classified into 25 groups (CAIs). The total number of homologous clones isolated is indicated.

${ }^{c}$ High score, an indication of the significance of the homology, were obtained with the BLASTX search algorithm.

d The value is calculated from the fomula $E=\mathrm{N} / 2 \mathrm{~S}^{\prime}$. To achieve a marginally significant $E$ value of 0.05 , a normalized score of $\geq 38$ bits is necessary (see Altschul et al. 1997). 
volved in the formation of disulfide bridges were conserved in osmotin-like proteins of other organisms (Fig. 2D). The partial amino acid sequences of CAI19 also were about $80 \%$ homologous to osmotin-like proteins from potato, tobacco, and tomato. The partial amino acid sequences of CAI23 are shown in Figure 2E. They contained a potential signal peptide sequence at amino acid positions 1 to 14 , and two membrane-associated helix sequences at positions 3 to 23 , and 70 to 89 , respectively. The $\mathrm{N}$-terminal partial sequences also contained a potential $\mathrm{N}$-glycosylation site, indicating that this gene may encode an extracellular glycoprotein (Fig.
2E, asterisk). The $C A I 23$ protein was about $50 \%$ homologous in amino acids to the LRR protein of Sorghum bicolar SLRR (Hipskind et al. 1996) and 57\% homologous to that of Lycopersicon esculentum LRP (Tornero et al. 1996).

To examine the expression of transcripts of $C A I$ genes in more detail, Northern (RNA) blot analyses were performed with each of 25 CAI cDNAs obtained. Total RNAs were extracted from the leaves and stems of pepper plants treated with pathogens and abiotic elicitors at the six-leaf stage (Jung 1998). In particular, pepper leaves infiltrated with the avirulent strain Bv5-4a show an HR characterized by development
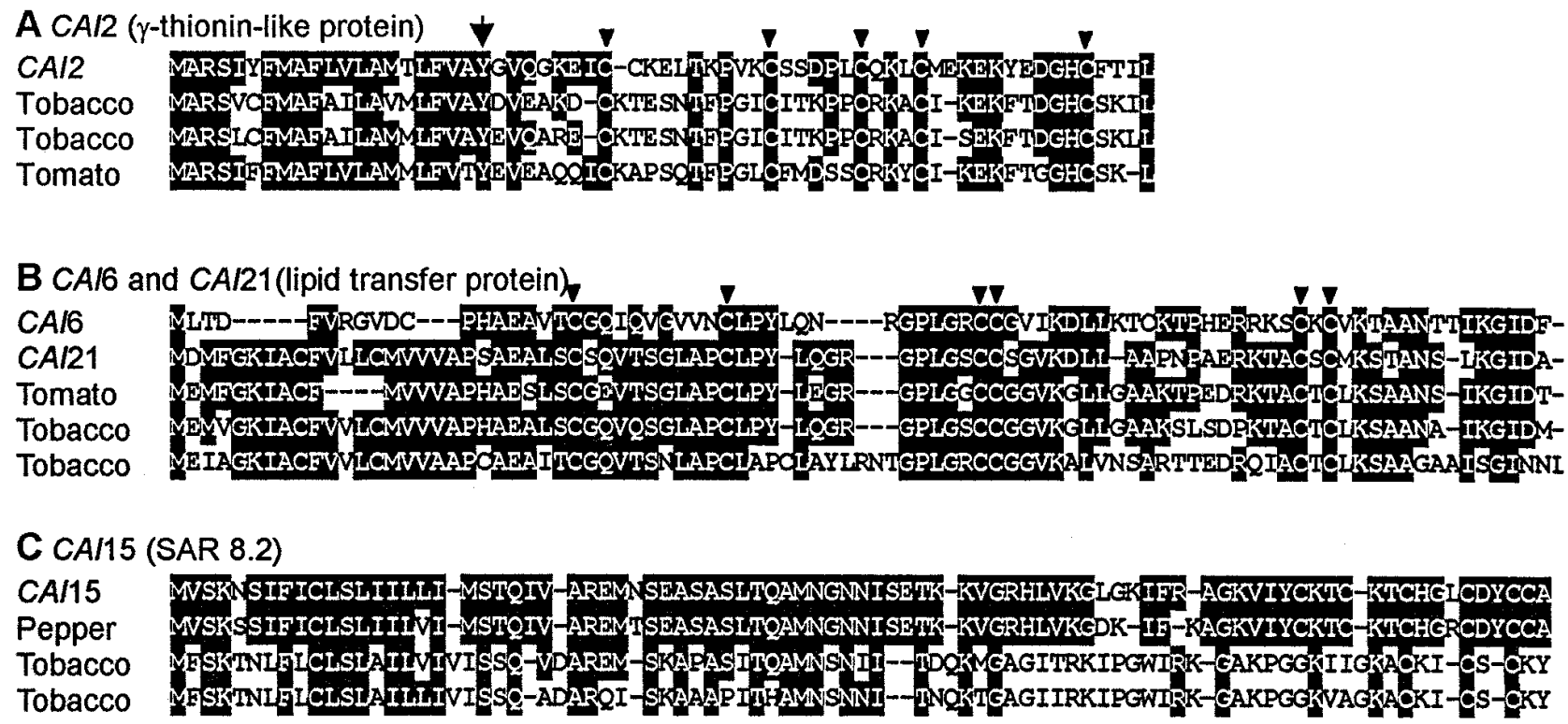

D CAl19 (osmotin-like protein)

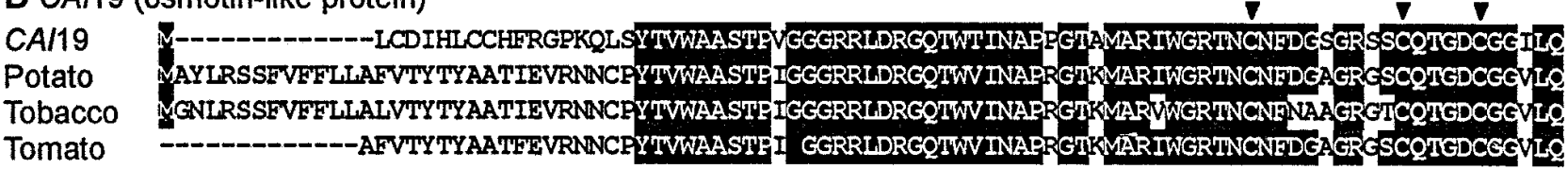

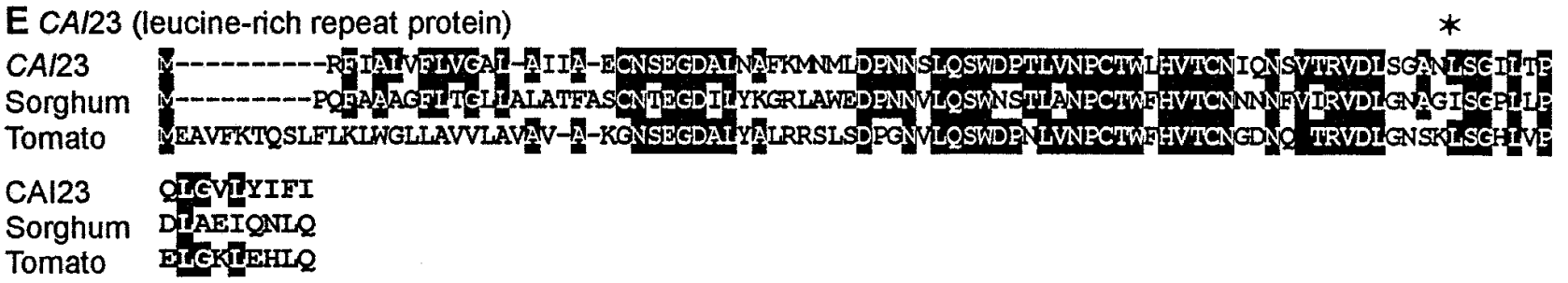

Fig. 2. Sequence analyses of the CAI2, CAI6, CAI15, CAI19, CAI21, and CAI23 cDNA. A, Comparisons of deduced amino acid sequences of CAI2 (accession no. AF082705) with $\gamma$-thionin-like proteins from Nicotiana excelsior (accession no. AB005266; Yamada et al. 1997), Lycopersicon esculentum 95 (accession no. S57809; Milligan and Gasser 1995), and Nicotiana tabacum (accession no. P32026; Gu et al. 1992). Triangles ( $\mathbf{\nabla}$ ) indicate conserved cysteine residues in all thionin-like proteins. An arrow indicates the tyrosine residue. B, Comparison of deduced amino acid sequences of CAI6 and CAI21 (accession nos. AF082710, AF082725) with lipid transfer proteins from L. esculentum (accession no. U81996; Plant et al. 1991), N. tabacum (accession no. D13952; Masuta et al. 1992), and N. tabacum (accession no. X62395; Fleming et al. 1992). Triangles ( $\mathbf{\nabla}$ ) indicate conserved cysteine residues in all lipid transfer proteins. C, Comparison of deduced amino acid sequences of CAI15 (accession no. AF082719) with SAR 8.2 from Capsicum annuum (S. C. Lee and B. K. Hwang, unpublished data), and N. tabacum (accession no. M97194; Ward et al. 1991). D, Comparison of deduced amino acid sequences of CAI19 (accession no. AF082723) with osmotin-like proteins from Solanum commersonii (accession no. X67121; Zhu et al. 1993), N. tabacum (accession no. X65700; Melchers et al. 1993), and Solanum lycopersicum (accession no. X70787; Rodrigo et al. 1993). Triangles ( $\mathbf{\nabla}$ ) indicate conserved cysteine residues. E, Comparison of deduced amino acid sequences of CAI23 (accession no. AF082727) with leucine-rich repeat proteins from Sorghum bicolor (accession no. U62279; Hipskind et al. 1996), and L. esculentum (accession no. X95269; Tornero et al. 1996). Asterisk indicates a potential N-glycosylation site. Gray boxes indicate identical amino acid residues. Dashes mark spacing in amino acid sequences done for proper alignment. 
of yellow, localized, necrotic lesions at the infiltrated site. Infiltration with the virulent strain Ds1 developed a susceptible response on pepper leaves, which showed water-soaking and yellowing as observed by Lee and Hwang (1996). The plants infected with virulent isolate S197 had rapidly growing stem lesions, whereas the plants infected with avirulent isolate CBS178.26 had superficial brownish speckling that developed slowly on the stems. Twelve of 25 CAI cDNA groups were strongly or differentially expressed in pepper leaves and stems

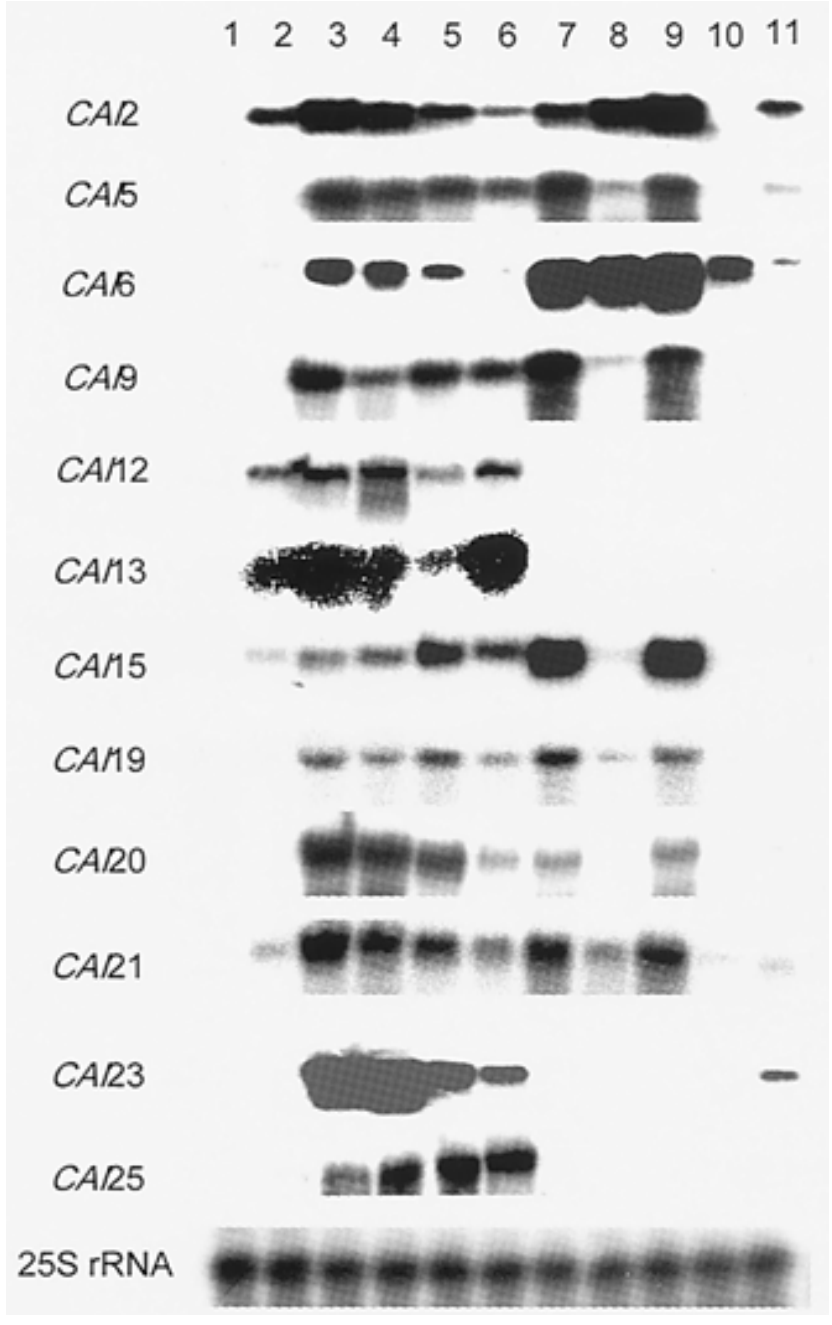

Fig. 3. Northern (RNA) blot analyses of transcript levels of $C A I$ genes differentially induced in pepper plants treated with pathogens, abiotic elicitors, and wounding at the six-leaf stage. Clone designation $(C A I 2, \gamma-$ thionin-like protein; CAI5, osmotin-like protein I; CAI6, lipid transfer protein; $C A I 9$, chitinase class I; $C A I 12$, stellacyanin-like protein; $C A I 13$, unknown gene; CAI15, SAR8.2; CAI19, osmotin-like protein II; CAI20, $\beta$-1,3-glucanase; $C A I 21$, lipid transfer protein II; $C A I 23$, leucine-richrepeat protein; $C A I 25$, auxin-repressed protein) is indicated at the left of each panel. Lane 1: healthy leaves; lane 2: healthy stems; lanes 3 and 4: leaves $24 \mathrm{~h}$ after inoculation with virulent strain DS1 and avirulent strain Bv5-4a of Xanthomonas campestris pv. vesicatoria, respectively; lanes 5 and 6: stems $48 \mathrm{~h}$ after inoculation with virulent isolate S197 and avirulent isolate CBS 178.26 of Phytophthora capsici, respectively; lanes 7 to 10 : leaves $24 \mathrm{~h}$ after treatment with ethephon $(10 \mathrm{mM})$, salicylic acid (5 mM), methyl jasmonate $(100 \mu \mathrm{M})$, and DL- $\beta$-amino-nbutyric acid $(2,000 \mu \mathrm{g} / \mathrm{ml})$, respectively; and lane 11: wounded leaves. For wounding, pepper leaves were rubbed with 3MM paper (Whatman). As a loading control, blots were probed with a Capsicum annuиm $25 \mathrm{~S}$ ribosomal RNA probe. by either pathogen infection or abiotic elicitor treatment, although not detected in the healthy, uninfected leaves or stems (Fig. 3). Accumulation of all 12 CAI transcripts was induced in pepper leaves infected with $X$. campestris pv. vesicatoria, irrespective of compatible or incompatible interaction (Fig. 3, lanes 3 and 4). However, their $C A I$ transcripts, except for the unknown $C A I 13$ gene, were more strongly induced in the compatible interaction than in the incompatible interaction at $48 \mathrm{~h}$ after inoculation with $P$. capsici on pepper stems (Fig. 3, lanes 5 and 6). The expression patterns of the 25 CAI cDNAs could be classified into two categories. In the first case, accumulation of $C A I$ gene transcripts was differentially induced in pepper leaves and stems by either pathogen infection or abiotic elicitor treatment, although not detected in healthy leaves or stems (Fig. 3). In the second case, accumulation of CAI transcripts was stimulated in leaves and stems by pathogen infection. Some CAI genes, CAI8, CAI10, CAI11, and CAI16, were more strongly expressed in pepper leaves and stems upon pathogen attack and abiotic elicitor treatment than in healthy, uninfected leaves and stems (data not shown). In general, many PR genes are known to be induced in the compatible and incompatible interactions of pathogens with host plants. However, the expression of some defense-related genes was found to be more rapid and pronounced in the incompatible interaction than in the compatible interaction (Dong et al. 1991; Chittoor et al. 1997). Accumulation of CAI gene transcripts was strongly induced in pepper leaves or stems infected with $X$. campestris pv. vesicatoria or $P$. capsici, irrespective of compatible or incompatible interaction (Fig. 3, lanes 3 to 6), suggesting that the transcripts of $C A I$ genes may be triggered in pepper plants by biotic elicitors such as phytopathogenic bacteria and fungi. Wounding did not induce or weakly induced $C A I$ gene transcription (Fig. 3, lane 11), indicating that these $C A I$ genes may not be involved in the wound response of pepper plants.

To determine whether or not transcripts of CAIs were expressed by abiotic elicitors, we applied ethephon, methyl jasmonate (MeJA), SA, and BABA to pepper leaves. In this study, accumulation of $C A I$ gene transcripts was induced in pepper leaves by some abiotic elicitors. Treatments with either ethephon or MeJA markedly induced transcripts of $C A I$ genes, but did not for CAI12, CAI13, CAI23, and CAI25 genes (Fig. 3, lanes 7 and 9). Only three $C A I$ genes, CAI2, CAI6, and $C A I 21$, were expressed in leaves treated with SA (Fig. 3, lane 8). In a comparison of CAI6 and CAI21 showing homology to putative lipid transfer protein but different nucleotide sequences, CAI6 transcripts were strongly expressed in leaves by either SA or BABA treatment, whereas expression of CAI21 transcripts was very low in leaves treated with SA and did not occur at all by BABA treatment (Fig. 3, lanes 8 and 10).

In general, the application of SA can induce local resistance, and PR genes are expressed in the SA-treated tissue in some plants, such as Arabidopsis (Uknes et al. 1992), cucumber (Métraux et al. 1990), and tobacco (Ward et al. 1991). However, CAI9, CAI15, CAI19, and CAI20 genes encoding putative class I chitinase, SAR 8.2, osmotin (PR-5), and $\beta$ 1,3-glucanase, respectively, were pronouncedly expressed in pepper leaves in response to ethephon and MeJA treatments but were weakly or not at all induced in SA-treated pepper leaves. These results strongly suggest that exogenous SA may not be a strong signal molecule to activate defense-related 
genes in pepper plants, because SA application did not induce resistance reactions to plant pathogens in pepper plants (data not shown).

In contrast to SA, exogenous ethylene seemed to function as a strong, steady signal molecule in the accumulation of $C A I$ gene transcripts in pepper plants. Ethylene, as a plant hormone, affects the induction of PR protein accumulation (Roby et al. 1986; Felix and Meins 1987) as well as plant growth and development (Abeles et al. 1992). Van Loon (1977) reported earlier that accumulation of PR proteins was detected in tobacco leaves treated with ethephon. In the application of ethephon, a chemical releasing gaseous ethylene, however, we should examine whether or not hydrochloric acid $(\mathrm{HCl})$ and phosphonic acid $\left(\mathrm{H}_{3} \mathrm{PO}_{3}\right)$, when applied to plants as breakdown products of ethephon, induce transcripts of some PR genes. The results revealed that treatment with the two chemicals did not induce accumulation of these PR-gene transcripts in pepper plants (data not shown).

MeJA was supposed to act in a volatile, gaseous form as a functional analogue to the plant hormone ethylene, not only to modulate plant development but also to induce plant resistance to pathogens in higher plants (Creelmann and Mullet 1997). A low concentration of endogenous jasmonate was found to express genes encoding proteinase inhibitors (Farmer and Ryan 1990), thionin (Andresen et al. 1992), and osmotin (Xu et al. 1994). It has also been demonstrated that exogenous application of jasmonic acid (JA) and MeJA induced resistance in potato and tomato against $P$. infestans (Cohen et al. 1993). Exogenous application of MeJA in this study caused accumulation of some $C A I$ gene transcripts. Transcripts of some $C A I$ genes were abundantly induced in pepper leaves by ethephon and MeJA treatment. This is well supported by the findings of Penninckx et al. (1996) that transcripts of a plant defensin gene were pronouncedly induced in Arabidopsis after treatment of leaves with MeJA or ethylene.

Northern blot analysis also revealed that application of $\mathrm{BABA}$ on pepper leaves triggered induction of transcripts of the CAI6 (putative lipid transfer protein) gene. BABA has been used as an abiotic elicitor to induce resistance in various plants including tomato (Cohen 1993), tobacco (Cohen 1994), cotton (Kalix et al. 1996), and pepper (Sunwoo et al. 1996) against different groups of fungal pathogens. However, BABA did not seem to function as a signal molecule to activate other CAI genes.

CAI2 and CAI6 genes encoding putative thionin and lipid transfer protein, respectively, were strongly expressed in pepper leaves infected by pathogens or treated with ethephon, MeJA, and SA. Recently, the thionin encoded by Arabidopsis Thi2.1 was found to be strongly induced by either pathogen attack or MeJA but not by SA (Epple et al. 1995). These results of our study suggest that pepper thionin and lipid transfer proteins may be significant in the activation of defense responses to plant diseases and chemical stresses.

Transcripts of CAI12 (putative stellacyanin-like protein gene), CAI13 (unknown gene), CAI23 (putative LRR protein gene), and $C A I 25$ (putative auxin-repressed protein gene) also were strongly expressed in pepper leaves or stems by pathogen infection, but were weakly or not at all induced by abiotic elicitor treatments (Fig. 3). These results suggest that these $C A I$ genes might be induced directly or indirectly by elicitors from plant pathogens, but not be part of the pathways influ- enced by abiotic elicitors, or be defense-related genes whose action is upstream of the points of the pathways where abiotic elicitors have an inducing effect. Transcripts of CAI12 (putative stellacyanin-like protein gene) and CAI23 (putative LRR protein gene) were more rapidly expressed than other $C A I$ genes in pepper leaves and stems during pathogen development (data not shown). These CAI genes may encode some key enzymes associated with defense response pathways (Stone and Walker 1995).

\section{ACKNOWLEDGMENTS}

This work was financially supported by the Korea Science and Engineering Foundation. We also thank P. A. Rebeiz for critical reading of the manuscript.

\section{LITERATURE CITED}

Abeles, F. B., Morgan, P. W., and Saltveit, M. E. 1992. Ethylene in Plant Biology. 2nd ed. Academic, San Diego, CA.

Alexander, D., Goodmann, R. M., Gut-Rella, M., Glascock, C., Weymann, K., Friedrich, L., Maddox, D., Ahl-Goy, P., Luntz, T., Ward, E., and Ryals, J. 1993. Increase tolerance to two oomycetes pathogens in transgenic tobacco expressing pathogenesis-related protein 1a. Proc. Natl. Acad. Sci. USA 90:7327-7331.

Altschul, S. F., Madden, T. L., Schaffer, A. A., Zhang, J., Zhang, Z., Miller, W., and Lipman, D. J. 1997. Gapped BLAST and PSI-BLAST: A new generation of protein database search programs. Nucleic Acids Res. 25:3389-3402.

Andresen, L., Becker, W., Schluter, K., Burges, J., Parthier, B., and Apel, K. 1992. The identification of leaf thionin as one of the main jasmonate-induced proteins of barley (Hordeum vulgare). Plant Mol. Biol. 19:193-204.

Bohlmann, H. 1994. The role of thionin in plant protection. Crit. Rev. Plant Sci. 13:1-1.

Bohlmann, H., Clausen, S., Behnke, S., Giese, H., Hiller, C., ReimannPhilipp, U., Schreder, G., Barkhort, V., and Apel, K. 1988. Leafspecific thionins of barley - a novel class of cell wall proteins toxic to plant-pathogenic fungi and possibly involved in the defense mechanism of plants. EMBO J. 7:1559-1565.

Bol, J. F., Linthorst, H. J. M., and Cornelissen, B. J. C. 1990. Plant pathogenesis-related proteins induced by virus infection. Annu. Rev. Phytopathol. 28:113-138.

Chittoor, J. M., Leach, J. E., and White, F. F. 1997. Differential induction of peroxidase gene family during infection of rice by Xanthomonas oryzae pv. oryzae. Mol. Plant-Microbe Interact. 10:861-871.

Cohen, Y. 1993. Local and systemic control of Phytophthora infestans in tomato plants by DL-3-amino-n-butanoic acids. Phytopathology 84: 55-59.

Cohen, Y. 1994. 3-Aminobutyric acid induces systemic resistance against Peronospora tabacina. Physiol. Mol. Plant Pathol. 44:273288.

Creelman, R. A., and Mullet, J. E. 1997. Biosynthesis and action of jasmonates in plant. Annu. Rev. Plant Physiol. Plant Mol. Biol. 48:35581.

Dong, X., Mindrinos, M., Davis, K. R., and Ausubel, F. M. 1991. Induction of Arabidopsis defense genes by virulent and avirulent Pseudomonas syringae strains and by a cloned avirulence gene. Plant Cell 3: 61-72.

Epple, P., Apel, K., and Bohlmann, H. 1995. An Arabidopsis thaliana thionin gene is inducible via a signal transduction pathway different from that for pathogenesis-related protein. Plant Physiol. 109:813820.

Farmer, E. E., and Ryan, C. A. 1990. Interplant communication: Airborne methyl jasmonate induces synthesis of proteinase inhibitors in plant leaves. Proc. Natl. Acad. Sci. USA 87:7713-7716.

Felix, G., and Meins, F. 1987. Ethylene regulation of $\beta$-1,3-glucanase in tobacco. Planta 172:386-392.

Fleming, A. J., Mandel, T., Hofmann, S., Sterk, P., de Vries, S. C., and Kuhlemeier, C. 1992. Expression pattern of a tobacco lipid transfer 
protein gene within the shoot apex. Plant J. 2:855-862.

Friedrich, L., Lawton, K., Ruess, W., Masner, P., Specker, N., Gut Rella, M., Meier, B., Dincher, S., Staub, T., Uknes, S., Métraux, J.-P., Kessmann, H., and Ryals, J. 1996. A benzothiadiazole derivative induces systemic acquired resistance in tobacco. Plant J. 9:61-70.

Gadea, J., Mayda, M. E., Conejero, V., and Vera, P. 1996. Characterization of defense-related genes ectopically expressed in viroid-infected tomato plants. Mol. Plant-Microbe Interact. 9:409-415.

Garcia-Olmedo, F., Molina, A., Segura, A., and Moreno, M. 1995. The defensive role of nonspecific lipid-transfer proteins in plants. Trends Microbiol. 3:72-74.

Gu, Q., Kawata, E. E., Morse, M. J., Wu, H. M., and Cheung, A. Y. 1992. A flower-specific cDNA encoding a novel thionin in tobacco. Mol. Gen. Genet. 234:89-96.

Jung, H. W. 1998. Isolation and characterization of pathogenesis-related cDNA genes from pepper leaves infected by Xanthomonas campestris pv. vesicatoria. M.S. thesis. Korea University, Seoul.

Hipskind, J. D., Nicholson, R. L., and Goldsbrough, P. B. 1996. Isolation of a cDNA encoding a novel leucine-rich repeat motif from Sorghum bicolar inoculated with fungi. Mol. Plant-Microbe Interact. 9: 819-825.

Kalix, S., Anfoka, G., Li, Y., Stadnik, M., and Buchenauer, H. 1996. Induced resistance in some selected crops-prospects and limitations. Pages 453-460 in: Modern Fungicides and Antifungal Compounds. H. Lyr, R. E. Rusell, and H. D. Sisler, eds. Interact, Andover, UK.

Keith, C. S., Hoang, D. O., Barrett, B. M., Feigelman, B., Nelson, M. C., Thai, H., and Baysdorfer, C. 1993. Partial sequence analysis of 130 randomly selected maize cDNA clones. Plant Physiol. 101:329-332.

Kessmann, H., Staub, T., Hofmann, C., Maetzke, T., Herzog, J., Ward, E., Uknes, S., and Ryals, J. 1994. Induction of systemic acquired disease resistance in plants by chemicals. Annu. Rev. Phytopathol. 32: 439-459.

Kim, Y. J., and Hwang, B. K. 1994. Differential accumulation of $\beta-1,3-$ glucanase and chitinase isoforms pepper stems infected by compatible isolates of Phytophthora capsici. Physiol. Mol. Plant Pathol. 45:195209.

Kim, Y. J., and Hwang, B. K. 1996. Purification, N-terminal amino acid sequencing and antifungal activity of chitinases from pepper stems treated with mercuric chloride. Physiol. Mol. Plant Pathol. 48:417432.

Kim, Y. J., and Hwang, B. K. 1997. Isolation of a basic 34-kilodalton $\beta$ 1,3-glucanase with inhibitory activity against Phytophthora capsici from pepper stems. Physiol. Mol. Plant Pathol. 50:103-115.

Kobe, B., and Deisenhofer, J. 1994. The leucine-rich repeat: A versatile binding motif. Trends Biol. Sci. 19:415-421.

Kouchi, H., and Hata, S. 1993. Isolation and characterization of novel nodulin cDNAs representing genes expressed at early stages of soybean nodule development. Mol. Gen. Genet. 238:106-119.

Lee, Y. K., and Hwang, B. K. 1996. Differential induction and accumulation of $\beta$-1,3-glucanase and chitinase isoforms in the intercellular space and leaf tissues of pepper by Xanthomonas campestris pv. vesicatoria infection. J. Phytopathol. 144:79-87.

Ling, P., and Pardee, A. 1992. Differential display of eukaryotic messenger RNA by means of polymerase chain reaction. Science 257: 967-971.

Linthorst, H. J., Melchers, L. S., Mayer, A., van Roekel, J. S., Cornelissen, B. J., and Bol, J. F. 1990. Analysis of gene families encoding acidic and basic $\beta$-1,3-glucanases of tobacco. Proc. Natl. Acad. Sci. USA 87:8756-8760.

Masuta, C., Furuno, M., Tanaka, H., Yamada, M., and Koiwai, A. 1992. Molecular cloning of a cDNA clone for tobacco lipid transfer protein and expression of the functional protein in Escherichia coli. FEBS Lett. 311:119-123.

Melchers, L. S., Sela-Buurlage, M. B., Vloemans, S. A., Woloshuk, C. P., Van Roekel, J. S., Pen, J., van den Elzen, P. J., and Cornelissen, B. J. 1993. Extracellular targeting of the vacuolar tobacco protein AP24, chitinase and $\beta$-1,3-glucanase in transgenic plants. Plant Mol. Biol. 21:583-593.

Métraux, J.-P., Signer, H., Ryals, J., Ward, E., Wyss-Benz, M., Gaudin, J., Raschdorf, K., Schmid, E., Blum, W., and Inverardi, B. 1990. Increase in salicylic acid at the onset of systemic acquired resistance in cucumber. Science 250:1004-1006.

Milligan, S. B., and Gasser, C. S. 1995. Nature and regulation of pistilexpressed genes in tomato. Plant Mol. Biol. 28:691-711.

Penninckx, I. A. M., Eggermont, K., Terras, F. R. G., Thomma, B. P. H. J., De Samblanx, G. W., Buchala, A., Métraux, J.-P., Manners, J. M., and Broekaert, W. F. 1996. Pathogen-induced systemic activation of a plant defensin gene in Arabidopsis follows a salicylic acid-independent pathway. Plant Cell 8:2309-2323.

Plant, A. L., Cohen, A., and Bray, E. A. 1991. Nucleotide sequence and spatial expression pattern of a drought- and ABA-induced gene of tomato. Plant Physiol. 97:900-906.

Roby, D., Toppan, A., and Esquerre-Tugaye, M. T. 1986. Cell surfaces in plant-microorganism interactions. VI. Elicitors of ethylene from Colletotrichum lagenarium trigger chitinase activity in melon plants. Plant Physiol. 81:228-233.

Rodrigo, I., Vera, P., Tornero, P., Hernandez-Yago, J., and Conejero, V. 1993. cDNA cloning of viroid-induced tomato pathogenesis-related protein P23. Characterization as a vacuolar antifungal factor. Plant Physiol. 102:939-945.

Stone, J. M., and Walker, J. M. 1995. Plant protein kinase families and signal transduction. Plant Physiol. 108:451-457.

Sunwoo, J. Y., Lee, Y. K., and Hwang, B. K. 1996. Induced resistance against Phytophthora capsici in pepper plants in response to DL- $\beta$ amino-n-butyric acid. Eur. J. Plant Pathol. 102:663-670.

Terras, F. R. G., Schoofs, H. M. E., De Bolle, M. F. C., Van Leuven, F., Rees, S. B., Vanderleyden, J., Cammue, B. P. A., and Broekaert, W. F. 1992. Analysis of two novel classes of antifungal proteins from radish (Raphanus sativus L.) seeds. J. Biol. Chem. 267:15301-15309.

Tornero, P., Mayda, E., Gomez, M. D., Canas, L., Conejero, V., and Vera, P. 1996. Characterization of LRP, a leucine-rich repeat (LRR) protein from tomato plants that is processed during pathogenesis. Plant J. 10:315-330.

Uknes, S., Mauch-Mani, B., Moyer, M., Potter, S., Williams, S., Dincher, S., Chandler, D., Slusarenko, A., Ward, E., and Ryals, J. 1992. Acquired resistance in Arabidopsis. Plant Cell 4:645-656.

Van Loon, L. C. 1977. Induction by 2-chloroethylphosphonic acid of viral-like lesions, associated proteins, and systemic resistance in tobacco. Virology 80:417-420.

Ward, E. R., Uknes, S. J., Williams, S. C., Dincher, S. S., Wiederhold, D. L., Alexander, D. C., Ahl-Goy, P., Métraux, J.-P., and Ryals, J. 1991. Coordinated gene activity in response to agents that induce systemic acquired resistance. Plant Cell 3:1085-1094.

Xu, Y., Chang, P.-F. L., Liu, D., Narasimhan, M. L., Raghothama, K. G., Hasegawa, P. M., and Bressan, R. A. 1994. Plant defense genes are synergistically induced by ethylene and methyl jasmonate. Plant Cell 6:1077-1085.

Yamada, S., Komori, T., and Imaseki, H. 1997. cDNA cloning of $\gamma$ thionin from Nicotiana excelsior. Plant Physiol. 115:314.

Zhu, B., Chen, T. H., and Li, P. H. 1993. Expression of an ABAresponsive osmotin-like gene during the induction of freezing tolerance in Solanum commersonii. Plant Mol. Biol. 21:729-735. 